\title{
O COMPLEXO GRANULÍTICO DE SANTA CATARINA: UM ARCO INSULAR ARQUEANO?
}

\author{
M.C.H.Figueiredo ${ }^{1}$ \\ M.A.S.Basei ${ }^{1}$ \\ M.S.M.Mantovani ${ }^{2}$ \\ B.J.Fryer ${ }^{3}$
}

O Complexo Granulítico de Santa Catarina consiste predominantemente de uma seqüência básica a ácida e piroxenitos. Subordinadamente, ocorrem anortositos, trondhjemitos, anfibolitos e metassedimentos. Todas essas litologias têm um caráter gnáissico e foliação principal NE, com fortes mergulhos. Um metamorfismo regional de fácies granulito foi seguido por um metamorfismo, também regional, de fácies anfibolito e, restrito a zonas de falhas, um evento de fácies xisto-verde (e.g., HARTMANN et al., 1979; SILVA, 1984).

A abundância de granulitos básicos, principalmente como corpos lensóides a boudinados, e suas relações com os tipos ácido-intermediários, como contatos abruptos e formas angulosas ou manchas difusas, sugerem uma íntima relação entre os noritos e os enderbito-charno-enderbitos. Mega-enclaves, como em Barra Velha, representam grandes corpos máfico-ultramáficos preservados.

Terrenos arqueanos de alto grau (e.g., LEWISIAN-PARK \& TARNEY, 1987; NAPIER-SHERATON \& BLACK, 1983; QIANXI-JAHN \& ZHANG, 1984) são comumente constituídos dominantemente de gnaisses tonalíticos com enclaves básicos e, localmente, complexos máfico-ultramáficos e metassedimentos. Geralmente, os gnaisses são bimodais e seus componentes (máfico e silícico) têm petrogêneses diferentes.

\footnotetext{
${ }^{1}$ Departamento de Geologia Geral, Instituto de Geociências/USP, São Paulo.

2 Instituto Astronômico e Geofísico/USP, São Paulo.

3 Department of Earth Sciences, Memorial University of Newfoundland, Canadá.
} 
Os granulitos de Santa Catarina, por outro lado, parecem representar uma seqüência cálcio-alcalina cogenética (Fig. 1), com. os termos básicos correspondendo a toleítos de alto-Al e os ácido-intermediários a tonalitos de alto-Al e granodioritos. Os padrões de terras raras (HARTMANN, 1988) são semelhantes para todos os litotipos da seqüência, com fortes fracionamentos, enquanto os piroxenitos de Barra Velha têm padrões compatíveis com cumulatos de piroxênio (Fig. 2). A sugestão de que as rochas básicas seriam cogenéticas com as mais diferenciadas e a presença de piroxenitos, anortositos e texturas cumuláticas sugerem que cristalização fracionada seria um mecanismo dominante em sua gênese, com plagioclásio, olivina, clinopiroxênio, Ti-magnetita e apatita como as fases participantes.

Os granulitos de Santa Catarina apresentam empobrecimento em elementos incompatíveis, embora não tão pronunciado como o dos granulitos Lewisian (WEAVER \& TARNEY, 1980), e semelhança com rochas andinas e do Lewisian na distribuição dos elementos mais compatíveis, com características típicas de ambiente de subducção (Fig. 3). Geralmente o empobrecimento em elementos incompatíveis é considerado como uma remoção em fusões parciais ou fluidos carbônicos durante o metamorfismo de alto grau. TARNEY \& WEAVER (1987) sugeriram que os baixos teores desses elementos possam ser uma característica primária desses magmas tonalíticos.

Para as seqüências bimodais, tem-se sugerido (e.g., LEWISIAN-PARK \& TARNEY, 1987; TARNEY \& WEAVER, 1987) que os gnaisses máficos seriam produzidos por cristalização fracionada de toleítos, a baixa pressão, enquanto os gnaisses silicosos seriam coerentes com fusão parcial de anfibolitos, a mais alta pressão, em um ambiente de subducção rasa de crosta oceânica. Para Santa Catarina, a cogeneticidade das rochas básicas a ácidas sugere um modelo mais simples, de geração de toleíto de alto-Al por fusão parcial de manto, com granada como provável fase residual, e posterior diferenciação desse magma por cristalização fracionada, também em um ambiente de subducção. $\mathrm{O}$ tamanho relativamente pequeno do complexo e a ausência de crosta continental mais antiga, reconhecida, sugerem um ambiente de arco insular em vez de margem continental ativa.

\section{REFERÊNCIAS BIBLIOGRÁFICAS}

HARTMANN, L.A. (1988) Geoquímica de terras raras e geotermobarometria de granulitos de Dom Pedrito e Luís Alves, no extremo sul do Brasil. Geochimica Brasiliensis, 2:1-14. 
HARTMANN, L.A.; SILVA, L.C.; ORLANDI, V. (1979) O Complexo Granulítico de Santa Catarina. Acta Geologica Leopoldensia, 6:94-112.

JAHN, B. \& ZHANG, Z. (1984) Archean granulite gneisses from eastern Hebei Province, China: rare earth geochemistry and tectonic implications. Contributions to Mineralogy and Petrology, 85(3):224-243.

PARK, R.G. \& TARNEY, J. (1987) The Lewisian complex: a typical Precambrian high-grade terrain? In: R.G. PARK \& TARNEY (eds.) Evolution of the Lewisian and Comparable Precambrian High Grade Terrains. Oxford, Geological Society by Blackwell Scientific Publications. p.13-25 (Geological Society Special Publication, 27).

SHERATON, J.W. \& BLACK, L.P. (1983) Geochemistry of Precambrian gneisses: relevance for the evolution of the east Antarctic shield. Lithos, 16(4):273-296.

SILVA, L.C. (1984) Os terrrenos de médio e alto grau do Pré-Cambriano de Santa Catarina. In: CONGRESSO BRASILEIRO DE GEOLOGIA, 33., Rio de Janeiro, 1984. Anais. Rio de Janeiro, SBG. V.7, p.3069-3080.

TARNEY, J. \& WEAVER, B.L. (1987) Geochemistry of the Scourian complex: petrogenesis and tectonic models. In: PARK, R.G. \& TARNEY, J. (eds.) Evolution of the Lewisian and comparable precambrian high grade terrains. Oxford, Geological Society by Blackwell Scientific Publications. p.45-56 (Geological Society Special Publication, 27).

WEAVER, B.L. \& TARNEY, J. (1980) Rare earth geochemistry of Lewisian granulite-facies gneisses, Northwest Scotland: implications for the petrogenesis of the Archaean lower continental crust. Earth and Planetary Science Letters, 51(2):279-296. 

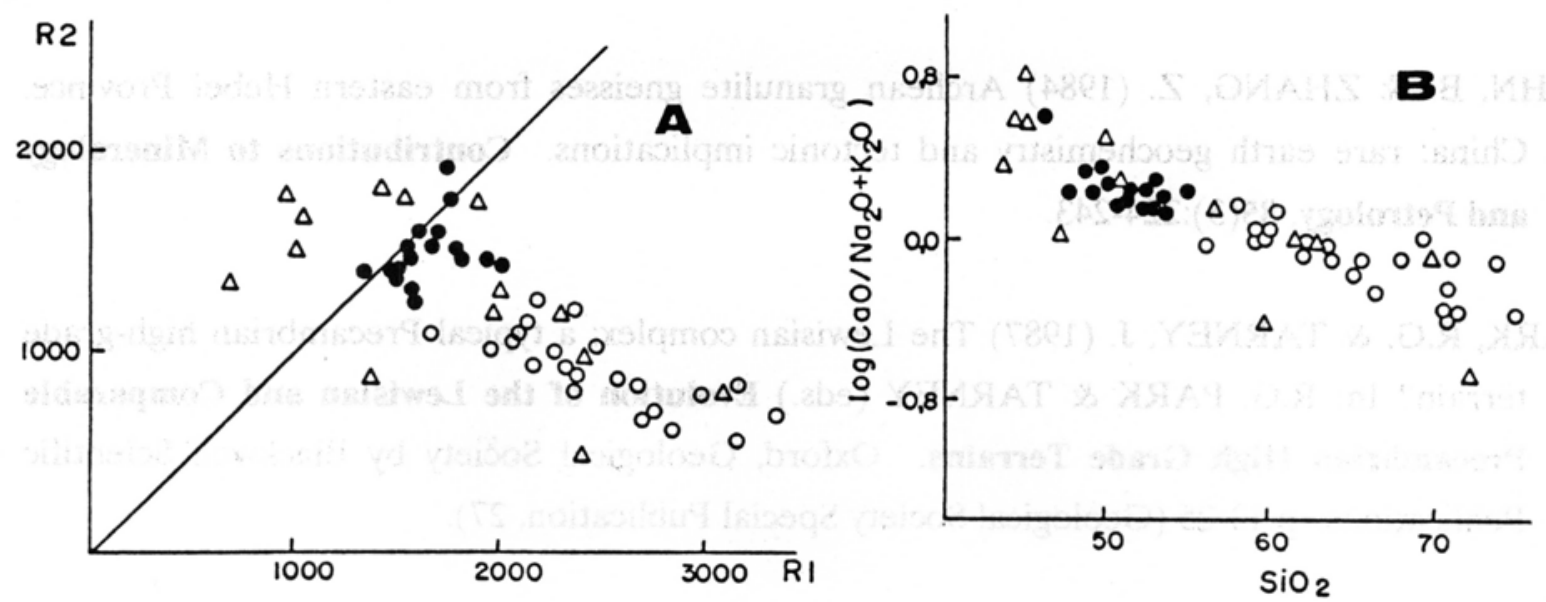

Figura 1 - Diagramas $R_{1}-R_{2}$ (A) e razão cálcio-álcalis vs. sílica (B). Simbologia: círculos cheios - granulitos básicos; ć́rculos vazados - granulitos ácido-intermediários; triângulos - rochas não cogenéticas.
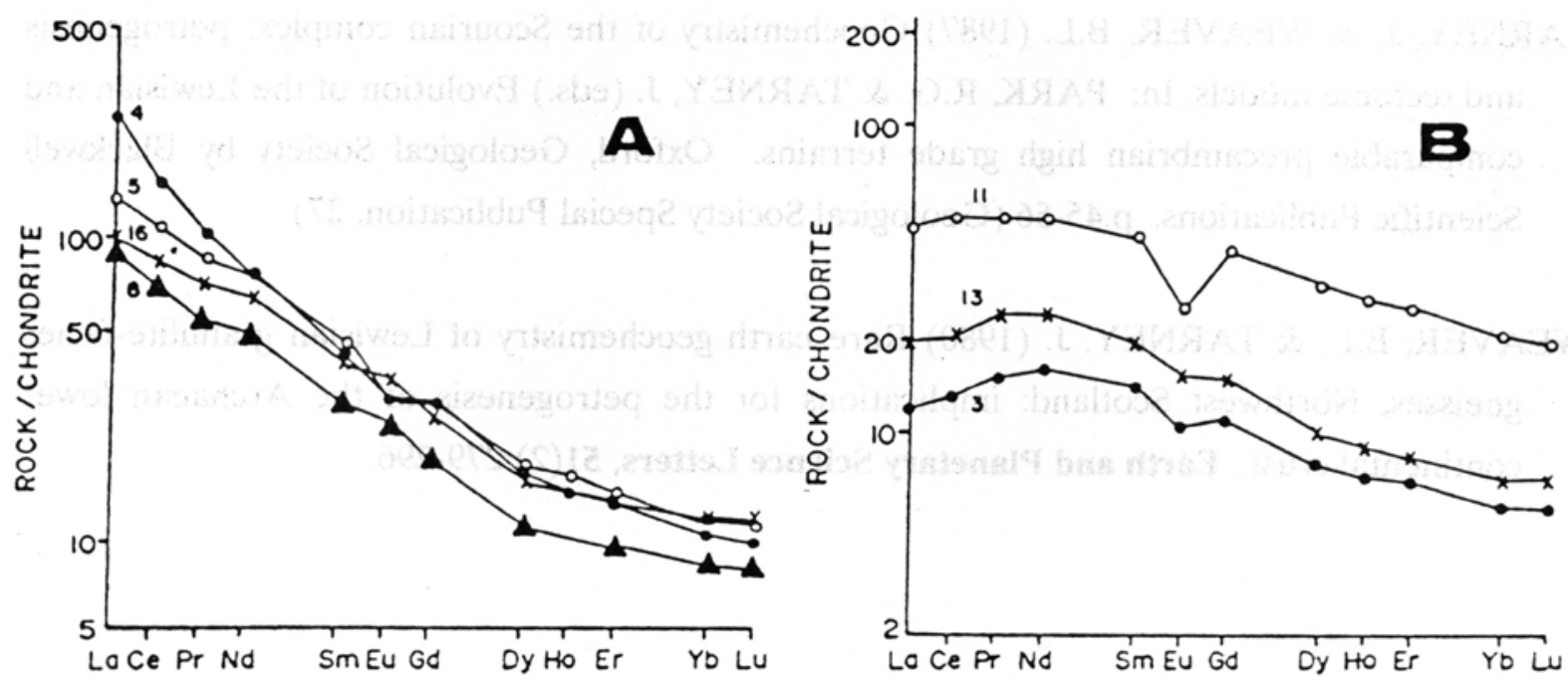

Figura 2 - Padrões de Terras Raras para granulitos básicos a ácidos de Luis Alves (A) e piroxenitos de Barra Velha (B). 


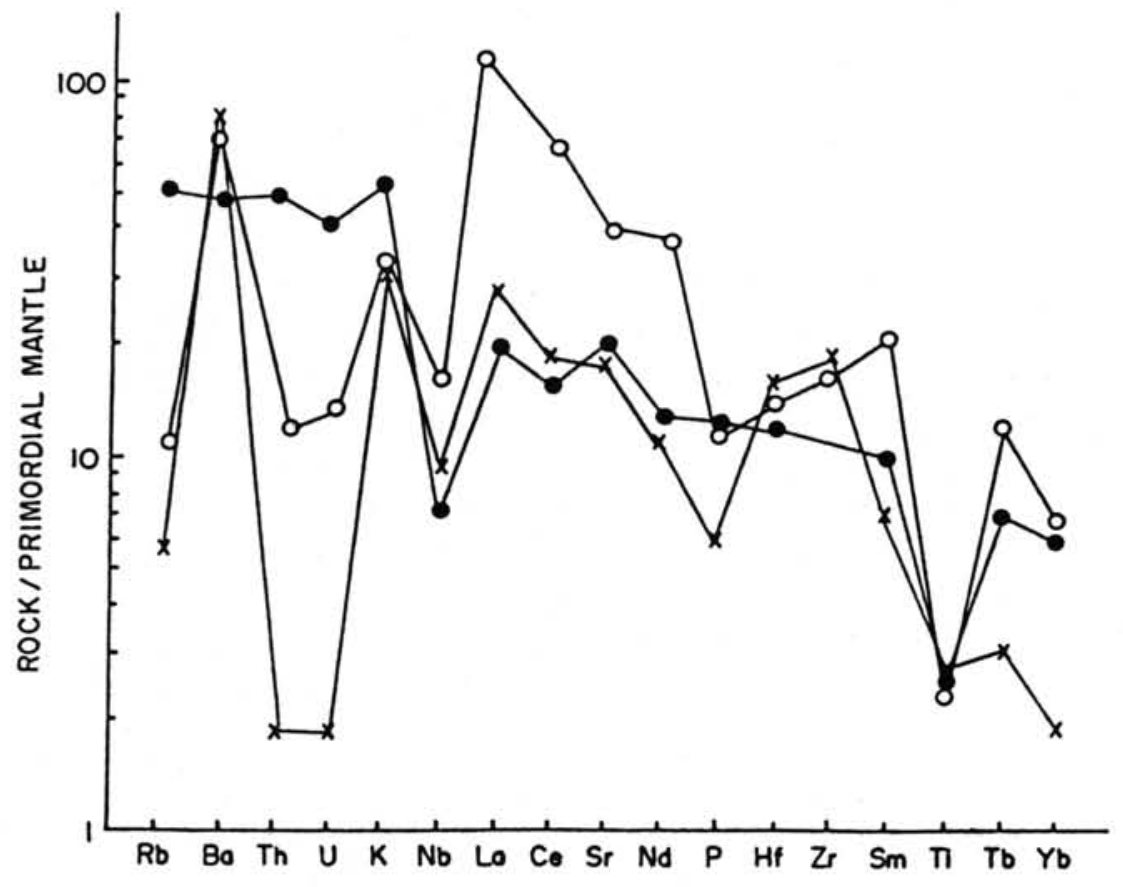

Figura 3 - Aranhograma para enderbito de Luis Alves (círculos vazados), enderbito Lewisian (xises) e tonalito andino (círculos cheios). 